\title{
POOR VITAMIN D STATUS IN HEALTHY MOTHERS AND INFANTS: RESOLUTION IN NEONATES ON 200 IU DAILY
}

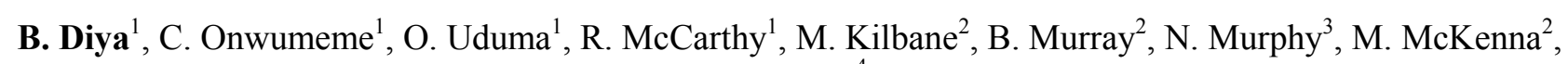
E. Molloy ${ }^{4}$

${ }^{1}$ Neonatal Intensive Care, National Maternity Hospital, Holles Street, ${ }^{2}$ Metabolism Laboratory, St Vincent's University Hospital, ${ }^{3}$ Dept Endocrinology, Children's University Hospital, ${ }^{4}$ National Maternity Hospital, Holles Street, UCD School of Medicine \& Medical Sciences, National Maternity Hospital, Holles Street, University College Dublin, Royal College of Surgeons of Ireland, Dublin, Ireland

Background and object: According to Institute of Medicine, serum 25-hydroxyvitamin D (S-25-OHD) $<30$ $\mathrm{nmol} / \mathrm{L}$ indicates high risk for rickets. Vitamin D status, as assessed by S-25-OHD, is often poor in normal healthy mothers and their infants in Northern latitudes. Routine supplementation (200 IU/d) of all newborns has recently commenced in Ireland The object of this study was to assess S-25OHD status in maternal and term umbilical cord samples and at follow-up in those neonates with $\mathrm{S}-25 \mathrm{OHD}<30 \mathrm{nmol} / \mathrm{L}$.

Methods: S-25-OHD levels were evaluated from maternal $(n=44)$ and umbilical cord samples $(n=56)$ from term normal pregnancies in a consecutive sample of cases. Parents of infants with S-25-OHD $<30 \mathrm{nmol} / 1$ $(\mathrm{n}=15)$ were invited to attend for repeat sampling.

Results: 115 samples included 44 maternal and 56 cord samples and 15 follow-up neonatal samples for infants with cord samples $<30 \mathrm{nmol} / 1$. The mean of cord blood 25OHD levels were significantly decreased compared with maternal levels. However the neonatal follow-up samples were significantly increased compared to maternal and cord levels in each subgroup (Table1).

Conclusions: We demonstrated a high prevalence of poor vitamin D status at the time birth in mothers and their infants that was rectified by low dose $(200 \mathrm{IU} / \mathrm{d})$ supplementation.

\begin{tabular}{|l|l|l|l|l|}
\hline Groups & Maternal $(\mathrm{n}=44)$ & Cord $(\mathrm{n}=56)$ & Infant $(\mathrm{n}=15)$ & p value \\
\hline Serum 25OHD & \multicolumn{2}{|l|}{} & \\
\hline All $(\mathrm{n}=115)$ & $42.8+/-21.0$ & $30.7+/-16.8$ & $61.8+/-13.8$ & $<0.001$ \\
\hline $\begin{array}{l}\text { No Follow-up } \\
(\mathrm{n}=100)\end{array}$ & $47.3+/-22.4$ & $33.0+/-16.1$ & NA & $<0.001$ \\
\hline Follow-up $(\mathrm{n}=15)$ & $30.3+/-9.2$ & $19.9+/-4.7$ & $63.3+/-14.5$ & $<0.001$ \\
\hline
\end{tabular}

[Table 1] 